\title{
A Crîse da Liga das Nações de 1926: Realismo Neoclássico, Multilateralismo e a Natureza da Política Externa Brasilleira*
}

\section{Braz Baracuhy**}

"Not a whit, we defy augury; there's a special providence in the fall of a sparrow."

William Shakespeare, Hamlet, ato V, cena II.

\section{Introdução}

\begin{abstract}
A Liga das Nações foi, até o momento de sua criação, a mais elaborada tentativa de organizar racionalmente as relações internacionais a partir de uma instituição multilateral. Como assinala o historiador Eric Hobsbawm, se a Primeira Guerra Mundial demarca o colapso
\end{abstract}

\footnotetext{
*Artigo recebido e aprovado para publicação em maio de 2006. As opiniões expressas neste artigo são de caráter pessoal e não refletem necessariamente aquelas do Ministério das Relações Exteriores ou do governo brasileiro.

***Diplomata, mestre em Relações Internacionais pelo Instituto de Relações Internacionais da Pontifícia Universidade Católica do Rio de Janeiro (IRI/PUC-Rio) e em Diplomacia pelo Instituto Rio Branco, Ministério das Relações Exteriores (IRBr/MRE), professor titular de Teoria das Relações Internacionais no IRBr/MRE. Foi visiting scholar do Departamento de Relações Internacionais da London School of Economics and Political Science (LSE).
}

CONTEXTO INTERNACIONAL Rio de Janeiro, vol. 28, n² 2, julho/dezembro 2006, pp. 355-397. 
do século XIX, a ordem internacional européia chega ao fim, em seu sentido clássico, com a Liga das Nações, uma organização internacional no tabuleiro multilateral, que deveria substituir as dinâmicas de poder tradicionais no tabuleiro geopolítico. Sua criação refletiu um desejo profundo de ruptura com o passado europeu da política internacional.

Ao final da Grande Guerra, o "equilíbrio de poder" tornara-se uma expressão odiosa. O presidente dos EUA, Woodrow Wilson, chegou à Conferência de Paz de Paris, em 1919, com seu projeto de uma nova ordem mundial, baseada na transposição dos valores e princípios do liberalismo político para o sistema internacional. Com a Liga das Nações, o direito deveria prevalecer sobre o poder, e os processos democráticos sobre os aristocráticos na condução das relações internacionais. O "equilíbrio de poder" seria substituído por uma "comunidade de poder".

O estabelecimento da Liga das Nações ocasionou a coexistência do velho e do novo na política internacional. Por um lado, os EUA, nova grande potência do sistema internacional, traziam o idealismo dos valores liberais que fundavam sua política doméstica para o campo internacional; por outro, permaneciam em cena as potências européias tradicionais, como a Inglaterra, a França e a Alemanha, habituadas às práticas da política do poder, desconfiadas dos novos ideais, ciosas de seus interesses vitais.

Como a política internacional do período, a política externa brasileira estava igualmente dividida entre o velho e o novo. O Barão do Rio Branco morreu em 1912, sem assistir ao final do século XIX, cujos ideais de política externa tão bem representou ${ }^{1}$. Em termos gerais, a atuação do Brasil na Liga deve ser entendida como a primeira grande questão diplomática depois da morte do Barão do Rio Branco. O regime republicano enfrentava seu batismo de fogo internacional no 
A Crise da Liga das Nações de 1926: Realismo Neoclássico, Multilateralismo...

campo das grandes potências, com o desafio de fazer política externa à sombra do Barão.

Com a nova organização internacional que se criava, dois tabuleiros, paralelos e superpostos, passavam a existir no sistema internacional. Acima do tabuleiro geopolítico clássico, no qual as potências européias praticavam há séculos a política do poder, surgia nova instância no tabuleiro multilateral. Organização universalista típica do século $\mathrm{XX}$ e dos critérios liberais de política internacional, a Liga das Nações foi expressão do novo jogo multilateral. E a crise do Conselho da Liga de 1926 pode ser vista como um nítido sinal de vida desse tabuleiro multilateral, capaz de exercer influência nas relações geopolíticas do tabuleiro tradicional.

Nas análises da crise de 1926, prevalece a tendência entre os historiadores a destacar o "fiasco" do Brasil na Liga das Nações (Santos, 2002). Partindo dessa premissa, variam apenas suas causas. Alguns culpam o presidente Artur Bernardes pelo uso da política externa como alucinógeno para a política doméstica (Macedo Soares); outros atribuem responsabilidade à França e à Inglaterra, usando o Brasil para conspirar secretamente contra a Alemanha (Heitor Lyra). O certo é que tem prevalecido a ênfase no processo de radicalização internacional do governo Bernardes, que culminaria na crise de 1926 , como definidor da natureza da política externa brasileira no período. Uma ação externa impulsiva e radical teria resultado no "fiasco" internacional.

Ao traçar minucioso panorama da participação do Brasil na Liga das Nações, Eugênio Vargas Garcia (2000:139) aponta o caso de "misperception" do governo brasileiro em suas demandas em Genebra pelo assento permanente no Conselho, buscando elevar o prestígio internacional do país, mas superestimando "as possibilidades de sucesso de sua aspiração". Stanley Hilton (1980) debruça-se também sobre as atitudes do presidente Bernardes, intransigente na política externa em razão das pressões domésticas que sofria da oposição. 
Clodoaldo Bueno compartilha a tese de Hilton e assinala o caráter instrumental da política externa "bonapartista” de Bernardes, servindo como fonte de prestígio e legitimidade doméstica para um governo impopular (Cervo e Bueno, 2002). Em exceção à tendência, Norma Breda dos Santos (1996) procura entender a crise a partir da configuração geral da política internacional, inserindo, nesse contexto mais amplo, os aspectos domésticos que caracterizavam a ação externa do Brasil à época.

O exame da crise de 1926, dentro do marco teórico das Relações Internacionais, sugere um processo mais amplo e complexo em curso no sistema internacional. Não parece ter sido o "prestígio" ou o "bonapartismo" o caráter essencial da política externa brasileira no período; tampouco o fiasco absoluto seu resultado. Seria uma interpretação estrita inferir-se de uma crise a natureza da política externa de um país.

Se for certo que as motivações do presidente Bernardes - sua personalidade, os constrangimentos domésticos de seu governo -, assim como as posições de seu inexperiente chanceler, o jornalista Félix Pacheco, tiveram papel no desenrolar da crise de 1926 e devem ser consideradas nas explicações sobre a política externa do período, a política internacional deve ser o ponto de partida. Somente com a compreensão das dinâmicas por posições de poder no sistema internacional da época pode-se vislumbrar como as elites de política externa percebiam tais movimentos, definiam seus interesses e traçavam suas estratégias.

O objetivo central do presente estudo é fornecer, a partir da teoria internacional fundamentada na história, um exame dos processos em curso na política internacional pós-Versalhes que conduziram à crise de 1926, uma visão das percepções, objetivos e estratégias de elites diplomáticas e, em especial, uma perspectiva sobre a natureza da política externa brasileira. Partindo de análise teórica na tradição do realismo neoclássico, vislumbro a possibilidade de conciliar variáveis 
A Crise da Liga das Nações de 1926: Realismo Neoclássico, Multilateralismo...

sistêmicas e domésticas em modelo explicativo. Procuro dar importância inicial às dinâmicas do sistema internacional do período que, traduzidas pelas percepções de uma elite nacional e articuladas a seus interesses e estratégias, explicariam a natureza da política externa brasileira. No processo, tento oferecer contribuição ao debate até então restrito a historiadores - sobre o suposto "fiasco" da posição brasileira na Liga. Creio que, considerando a nova disposição dos tabuleiros do sistema internacional, tenha sido, no âmbito da atuação externa do Brasil, um "vencer ao perder", parafraseando o presidente Artur Bernardes.

Na primeira parte deste artigo, examino questões teóricas relacionadas ao modelo de análise desenvolvido dentro da tradição do realismo neoclássico. Na segunda, em aplicação do modelo sugerido, procuro mostrar as dinâmicas de poder no sistema internacional relacionadas à crise de 1926 - o processo geopolítico europeu sobre a "questão alemã" e o processo multilateral brasileiro, com a busca de um assento permanente no Conselho da Liga das Nações. Examino igualmente como a elite de política externa do país percebia a nova ordem internacional e suas dinâmicas e qual a posição de poder que vislumbrava para o Brasil nessa ordem. Na conclusão, procuro compreender a natureza da política externa brasileira no período. O episódio de 1926, embora geralmente analisado como uma ação desastrosa da diplomacia brasileira, pode ser visto como um sinal dos novos tempos nas relações internacionais: o jogo complexo de interações entre os tabuleiros geopolítico e multilateral - e a capacidade de a política externa brasileira exercer influência nesse novo contexto.

\section{Um Modelo de Análise de Política Externa no Realismo Neoclássico}

O realismo não é uma teoria. Seria mais exato compreendê-lo como uma tradição político-filosófica das Relações Internacionais. Essa 
tradição realista abrange e confere unidade a diferentes teorias, que procuram oferecer um olhar analítico sobre a realidade internacional. Os contornos ontológicos centrais do realismo revelam-se na ênfase sobre o que dá aos conceitos de poder como elemento regulador da vida internacional e sobre a anarquia como condição estrutural da esfera política internacional (Soares de Lima, 2001; Walt, 2002).

Mesmo na tradição realista, a perspectiva epistemológica mais apropriada para capturar a realidade das relações internacionais é objeto de debates, variando desde abordagens "clássicas" (com raízes política, histórica, filosófica) a "científicas" (com raízes nos métodos das ciências naturais). Na tentativa de desenvolvimento de modelos rigorosos para análise das relações internacionais, a teoria da política internacional concebida por Kenneth Waltz representou ponto de inflexão ${ }^{2}$. A partir da publicação de Theory of International Politics (1979), marco do neo-realismo ou realismo estrutural, despontaram, dentro da tradição realista, vertentes teóricas que buscavam aprimorar e refinar a lógica waltziana.

$\mathrm{Na}$ teoria de Waltz, os resultados internacionais derivam de causas sistêmicas e não, como vislumbrava o realismo clássico, de variáveis pertencentes ao nível das unidades políticas. Na lógica dedutiva waltziana, o eixo desloca-se para os efeitos do sistema internacional. A estrutura do sistema seria composta de três elementos: o princípio ordenador (a anarquia); a função das unidades (como as unidades são funcionalmente similares, não teriam papel analítico); e a distribuição de poder entre grandes potências (polaridade). A interação entre estrutura e unidades se dá em lógica explicativa "descendente" (top-down). Os resultados internacionais partem da estrutura do sistema.

Nesse sentido, a teoria neo-realista serviria para explicar resultados internacionais; jamais para entender políticas externas específicas. 
Pressupondo uma constante no comportamento externo das unidades no sistema, como maximizadoras de segurança, o resultado internacional mais significativo que se depreende da teoria waltziana é a "contraposição de poder" (balance of power).

A teoria da contraposição de poder de Waltz, que prevê padrões recorrentes de grandes potências contrapondo grandes potências, é a expressão da estrutura do sistema internacional sobre a política externa dos Estados. As contraposições de poder teriam caráter não intencional, produto da política internacional (sistema) e não da política externa (unidades e seus propósitos). Um corolário do modelo waltziano é que a pressão da estrutura internacional, a restrição que impõe ao comportamento das unidades, supera os propósitos gerados internamente pelos Estados - isto é, os propósitos de sua política externa - na medida em que molda a interação das unidades. De modo mais amplo, o comportamento agregado do sistema internacional restringe o comportamento das unidades.

Com efeito, na lógica sistêmica de Waltz, não se faz necessário dotar a política externa das unidades de interesses diferenciados. Todas elas teriam, a priori, o mesmo propósito primário: a sobrevivência, ainda que, a posteriori, seus propósitos pudessem variar, desde a manutenção de sua posição no sistema até o domínio mundial. Nesse sentido, o neo-realismo, ao contrário do realismo clássico, considera que o sistema internacional é composto exclusivamente de Estados satisfeitos (Schweller, 1996).

A sobrevivência, definida por Waltz como a manutenção da posição da unidade no sistema, é objetivo primário dos Estados. Esse objetivo é alcançado pela maximização da segurança. Somente quando a sobrevivência está assegurada, os Estados podem buscar outros objetivos. A dedução a partir da estrutura anárquica do sistema internacional waltziano poderia ser vista do seguinte modo: 


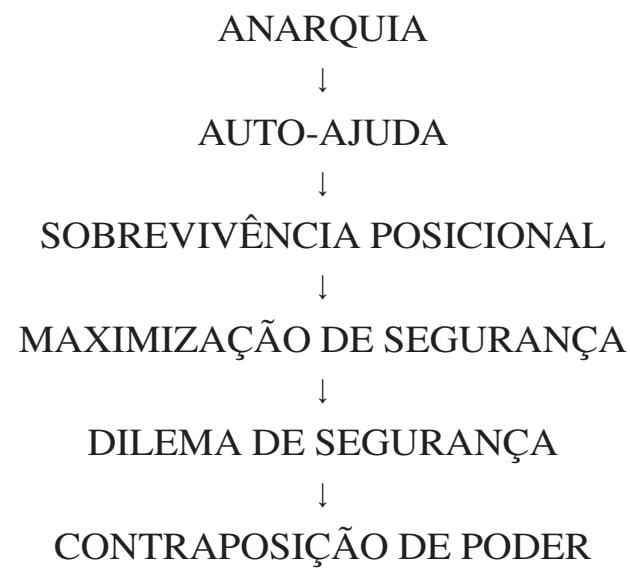

Como as unidades são idênticas, todos os Estados estariam dispostos a assumir custos e riscos altos para manter sua posição no sistema -e apenas custos e riscos baixos, marginais, para melhorá-la. Por isso, de acordo com Waltz (1979:126), “(...) a contraposição ('balancing'), e não a composição ('bandwagoning'), seria o comportamento induzido pelo sistema".

Aaron Friedberg (1988:4) corretamente aponta para o risco de toda teoria estrutural: sua tendência a degenerar em determinismo material. No modelo waltziano, a política externa aparecerá necessariamente como resposta contrapositiva (por meio de alianças ou de incremento do próprio poder nacional do Estado) a aumentos relativos de poder na estrutura do sistema. No entanto, nada há de inevitável ou automático nessa lógica, se considerarmos a percepção e as decisões dos líderes nacionais na história. Do ponto de vista teórico, a observação de Friedberg abre espaço para vislumbrar a contingência própria das decisões de política externa no curso da história internacional $^{3}$.

No debate contemporâneo dentro da tradição teórica realista surgiu importante conjunto de formulações a partir da década de 1990. Em 
artigo publicado no periódico World Politics, Gideon Rose (1998) denominou essa vertente "realismo neoclássico", da associação entre o neo-realismo e o realismo clássico. O realismo neoclássico reintroduz a dimensão histórica das relações internacionais (Wohlforth, 1993; Schweller, 1997; Zakaria, 1998). Ressurge a contingência das decisões de política externa, a escolha dos estadistas em seu tempo e espaço, em suas circunstâncias políticas e históricas. Como notou Stephen Walt (2002:210), “(...) enquanto Waltz insistiu que sua teoria não era uma teoria de política externa, a corrente neoclássica da teoria realista dá menos atenção às propriedades do sistema como um todo e se concentra primordialmente na explicação das decisões de políticas externas específicas".

Os modelos do realismo neoclássico procuram, em princípio, superar a separação rígida entre os níveis de análise, proposta por David Singer, os quais não se poderiam combinar ${ }^{4}$. Política internacional e política externa poderiam ser teoricamente integradas em modelos analíticos e tratadas a partir de uma abordagem clássica ${ }^{5}$. Ao contrário do que informa o neo-realismo, o comportamento atribuído às unidades pela estrutura do sistema internacional não seria unicamente a maximização da segurança. A posição relativa do Estado no sistema de poder internacional poderá estabelecer o parâmetro inicial de sua política externa. Mas a tradução das dinâmicas de poder no sistema internacional em comportamentos de política externa não é automática. As escolhas passam por variáveis intervenientes, expressas por certos fatores no nível doméstico das unidades.

Nesse sentido, as ações de política externa decorrem não de maneira automática das dinâmicas de poder no sistema internacional, mas passam por filtros intervenientes. No presente estudo, para examinar o caso específico da natureza da política externa brasileira na crise da Liga das Nações de 1926, procurarei dar ênfase ao seguinte modelo analítico: 


\section{Braz Baracuhy}

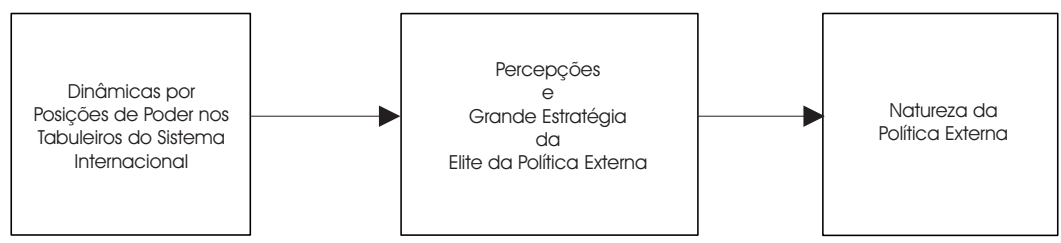

A relação entre essas variáveis indica que a natureza da política externa pode ser explicada a partir de dinâmicas por posições de poder nos tabuleiros do sistema internacional. Mas não de modo direto. No processo, intervêm (i) as percepções de uma elite de política externa sobre os movimentos de poder internacional e sobre o potencial de seu país, que dão contornos ao seu julgamento sobre interesses nacionais a serem perseguidos; e (ii) a grande estratégia traçada por essa elite para alcançar a posição de poder que vislumbra para seu país no sistema internacional.

Sugere-se a hipótese analítica de que o sistema internacional pós-Primeira Guerra Mundial passou a organizar-se em dois tabuleiros, paralelos e interdependentes: o geopolítico tradicional e o multilateral, superposto ao primeiro. A ascensão dos EUA à posição de grande potência provocou não somente mudanças no tabuleiro geopolítico, mas levou à criação de uma instituição no multilateral, a Liga das Nações, primeira grande organização política internacional. A emergência dessa organização no tabuleiro multilateral associou-se à presença dos EUA como grande potência e às idéias do liberalismo político internacional que passaram a defender e a difundir para a condução das relações internacionais.

Os dois tabuleiros, paralelos e superpostos, estariam inseridos no sistema internacional $^{6}$. Acima do geopolítico tradicional, consolida-se um multilateral. Com isso, cria-se um jogo diplomático complexo por posições de poder, com processos em cada um dos tabuleiros e, 
A Crise da Liga das Nações de 1926: Realismo Neoclássico, Multilateralismo...

sobretudo, com interconexões verticais entre tais. Dinâmicas de poder no multilateral passam a exercer influência considerável no geopolítico.

A avaliação das dinâmicas de poder é essencialmente estratégica. Para as elites de política externa, isso implica um jogo constante de percepções relativas, um processo contínuo de avaliação do próprio potencial em relação ao poder dos demais países, nos movimentos por posições internacionais. O potencial nacional de um país depende de seus recursos de poder - tangíveis e intangíveis -, de sua estrutura doméstica, de sua posição geográfica, de sua experiência histórica. Traduzido em estratégia e canalizado para a política externa, esse potencial poderá transformar-se em poder efetivo no sistema internacional.

Para compreender a natureza da política externa brasileira na crise da Liga das Nações de 1926, busco analisar como integrantes da elite de política externa percebiam tanto os movimentos de poder nos tabuleiros do sistema internacional, quanto o potencial nacional do país. Essas percepções e os objetivos definidos a partir delas se articulam em uma grande estratégia, que indicaria a posição de poder desejada pelo país no sistema.

A elite de política externa pode ser entendida, na linha proposta por José Murilo de Carvalho (1996), pelo critério posicional, isto é, a elite de política externa é constituída pelo grupo restrito de pessoas que ocupam posições formais de poder, decisivas para a condução da diplomacia de um país - presidentes, primeiros-ministros, chanceleres, embaixadores, dentre outros integrantes do círculo de poder da política internacional ${ }^{7}$.

A grande estratégia de um país deve ser compreendida, em seu sentido amplo, como uma concepção geral sobre a posição futura que este busca no sistema internacional. Tal concepção rege a direção dos objetivos e das estratégias e táticas diplomáticas, isto é, serve de parâ- 
metro para os cálculos da relação entre meios e fins na política externa (Kennedy, 1991; Howard, 2001). Como observa Charles Kupchan (2002:3), os Estados precisam de "um mapa conceitual do mundo e uma grande estratégia dele decorrente, com a finalidade de estabelecer uma relação entre seus objetivos internacionais e os meios de que dispõem para atingir tais objetivos". A escolha de uma grande estratégia é resultado de processo decisório, dentro da estrutura política doméstica do Estado. Desse processo político, sai vitoriosa determinada percepção do presente, do passado e do futuro no que tange à posição de poder do Estado no sistema internacional.

A grande estratégia dá forma e sentido aos interesses nacionais que serão buscados pela política externa. Na ausência de grande estratégia, a política externa torna-se reativa, vagando, sem rumo, em meio aos eventos e conjunturas internacionais. E não parece ter sido esse o caso da atuação diplomática brasileira durante os anos que teve por objetivo claro um assento permanente no Conselho da Liga das Nações.

Desde a preparação para a Conferência de Paz de 1919, o Brasil enxergou a oportunidade de ter um lugar reconhecido entre as grandes potências da nova ordem internacional que se instaurava. Ele participou da comissão que discutia a estrutura da Liga das Nações, e, nessa comissão, a atuação da chancelaria brasileira foi de alinhamento automático aos EUA. À época, essa posição se apresentava quase que natural à diplomacia brasileira, considerando uma das linhas características herdadas da chancelaria do Barão do Rio Branco: a inauguração do chamado "paradigma americanista" da política externa brasileira ${ }^{8}$.

Em fevereiro de 1919, o Projeto de Pacto da Liga das Nações estava concluído. A cúpula da organização seria o Conselho Executivo, formado por cinco potências permanentes (EUA, Inglaterra, França, 
A Crise da Liga das Nações de 1926: Realismo Neoclássico, Multilateralismo...

Itália e Japão) e quatro não permanentes (com apoio dos EUA, o Brasil é escolhido, ao lado da Bélgica, da Grécia e da Espanha).

O fato de o Brasil compartilhar, em um primeiro momento, as posições dos EUA em relação à importância da Liga e de reconhecer o prestígio da organização na política internacional não deve ser visto de maneira estática. Progressivamente, a busca por posição de poder central na Liga consolidou-se, tomou feição de interesse estratégico do país. À medida que avançava o jogo internacional e se moldavam as percepções das elites nacionais sobre o papel da Liga na nova ordem e sobre sua importância para a conquista de posição entre as grandes potências, a política externa brasileira revelava sua natureza de "status quo", de conquista incremental de poder dentro da ordem existente, como a define Hans Morgenthau.

Analisando a natureza de políticas externas, isto é, sua essência em certos momentos históricos, Morgenthau toma em conta as ações de política externa em relação à ordem internacional. Desse modo, será considerada uma política externa de "status quo" aquela que busca ou manter as posições de poder, ou ajustar as posições de poder dentro do marco de uma dada ordem internacional. Em contraste, a política externa revisionista, que busca alterar a ordem internacional, o “status quo" existente, e impor uma ordem alternativa, será considerada de "imperialismo" (Morgenthau, 1985:53, 56, 58). A política externa brasileira do período buscará ajustes de sua posição de poder dentro do quadro da própria ordem internacional, que tinha a Liga das Nações em seu centro: um ajuste do status de "membro temporário" a "membro permanente" do Conselho da Liga.

Nessa perspectiva, o Conselho da Liga afigurava-se como centro hierárquico de poder na nova organização internacional, e seus assentos permanentes deveriam assegurar, quase que automaticamente, a condição de grande potência na nova ordem internacional. 
A crise da Liga das Nações de 1926 deve ser entendida a partir do choque de dois longos processos da política internacional, nos tabuleiros geopolítico europeu e multilateral da organização. Movimentos por posições de poder em um dos tabuleiros passavam a influir nos processos do outro. Nessa dinâmica internacional, o privilégio dado ao tabuleiro multilateral e a experiência histórica do legado diplomático brasileiro condicionavam as percepções dos líderes nacionais, davam parâmetros a seus interesses, suas decisões estratégicas e táticas para a política externa. A política externa brasileira de "status quo" buscava ganhos de poder na nova ordem, que parecia destinada a reger o futuro das relações internacionais - e não contestar a ordem ou demonstrar gratuitamente certo poder de que não dispunha. Nessa busca, longe de representar um "fiasco" total, o episódio de 1926 significou uma vitória - ainda que efêmera - do multilateralismo nas relações internacionais.

\section{Posições de Poder, Percepções e Estratégias no Sistema Internacional}

A decisão tomada pela diplomacia brasileira, em 17 de março de 1926, de vetar a entrada da Alemanha na Liga das Nações terá parecido absurda a seus contemporâneos. O Conselho da Liga das Nações reunira-se naquele dia, em sessão secreta, para confirmar a Alemanha como membro permanente do Conselho. A votação seria mera formalidade. Desde os Acordos de Locarno ${ }^{9}$, a Europa parecia ter entrado em nova era de cooperação. As rivalidades do pós-Grande Guerra pareciam ter-se exaurido e, como conseqüência, nada mais natural do que a participação da Alemanha como potência legítima na ordem internacional. E, no entanto, o representante permanente do Brasil em Genebra anunciava que seu país vetaria a proposta.

O veto brasileiro, que tornou insustentável a permanência do país na Liga das Nações, foi o choque de longos processos. Há anos o Brasil 
A Crise da Liga das Nações de 1926: Realismo Neoclássico, Multilateralismo...

vinha seguindo sua agenda em Genebra com vistas à obtenção de uma cadeira permanente no Conselho, assim como, em outro sentido, as potências européias discutiam o destino da Alemanha.

A crise, porém, foi reveladora sobre o funcionamento desse tabuleiro do sistema internacional que começava a ganhar relevo no início do século XX - o multilateral -e suas implicações para os arranjos clássicos no tabuleiro geopolítico, a cujo funcionamento autônomo e irrestrito estavam acostumados os líderes das potências européias. $\mathrm{O}$ fato de a decisão do Brasil no plano multilateral ter barrado, ainda que momentaneamente, interesses vitais das potências européias no plano geopolítico é paradigmático de uma nova era que se iniciava nas relações internacionais. Nessa perspectiva, não importa que o sistema de segurança coletiva da Liga tenha fracassado mais tarde ou que a própria crise de 1926 já revelasse falhas desse sistema; importa sim destacar a existência do tabuleiro multilateral na política internacional, em cujos processos uma potência como o Brasil da época poderia ter peso significativo, exercendo influência nas relações tradicionais do tabuleiro geopolítico das grandes potências.

Como analisou o historiador Chris Leuchars, a crise do Conselho de 1926 deve ser entendida em dois âmbitos, como o choque entre dois processos distintos e independentes que se encontram no sistema internacional: de um lado, a questão da segurança européia e da entrada da Alemanha na Liga das Nações (no tabuleiro geopolítico); de outro, a culminação dos esforços brasileiros em obter um assento permanente no Conselho (no tabuleiro multilateral). A imagem de Leuchars (2001) é elucidativa: eram dois navios navegando em curso de colisão em um nevoeiro, com suas tripulações preocupadas exclusivamente com suas respectivas casas de máquinas. Quando se deram conta, foi impossível evitar a colisão.

Mas, para compreender a natureza da política externa brasileira no processo que culminou com o veto de 1926, torna-se indispensável examinar as percepções da elite diplomática sobre o que estava em 
jogo nos tabuleiros do sistema internacional e sobre o potencial do país para consecução dos interesses nacionais. Para o Brasil, contava a percepção de que o processo multilateral na Liga das Nações era definidor do futuro das relações internacionais e, por extensão, decisivo para a posição de poder a que aspirava na nova ordem que se formava.

\section{O processo europeu no tabuleiro geopolítico: "a questão alemã"}

A política internacional na Europa, as dinâmicas de poder envolvendo potências européias no tabuleiro geopolítico do pós-Grande Guerra, tinha, por pano de fundo, o chamado "problema alemão": "Se esse fosse resolvido, tudo estaria resolvido; se permanecesse sem solução, a Europa não conheceria a paz" (Taylor, 1996:40).

A segurança no continente europeu estava no cerne da "questão alemã". Os principais atores envolvidos eram o Reino Unido, a França e a Alemanha. O temor que a Alemanha despertava na França ainda estava aceso. No curto espaço de menos de cinqüenta anos, o território francês fora invadido duas vezes, alterando fundamentalmente o equilíbrio geopolítico europeu. A França passou a agir segundo o que Henry Kissinger (1994) denominou de "política externa do desespero", usando todos os expedientes, inclusive o Tratado de Versalhes, para impedir o desenvolvimento germânico. Em poucos momentos da história, a segurança e a proteção foram buscadas de forma tão obsessiva. A Linha Maginot representa o ápice da postura defensiva francesa, a expressão geopolítica de sua experiência histórica. O próprio sistema de segurança coletiva da Liga das Nações, na percepção dos líderes franceses que viveram a guerra, deveria ser um mecanismo direcionado contra a Alemanha, ou, na melhor das hipóteses, capaz de contê-la. 
A Crise da Liga das Nações de 1926: Realismo Neoclássico, Multilateralismo...

As perspectivas francesas de contar com alianças defensivas eram pouco promissoras. Por sua própria posição geográfica, a Inglaterra possuía uma definição de segurança distinta daquela buscada em termos absolutos pela França. Mas não interessava à Inglaterra se isolar dos assuntos continentais. A paz européia e a conciliação faziam parte da definição dos interesses britânicos, sobretudo em uma época em que as pressões populares pelo pacifismo ecoavam no Parlamento. Os líderes britânicos estariam dispostos a cooperar com a França, mas não a subscrever todas as invectivas francesas contra a Alemanha. Depois da Primeira Guerra, por razões psicológicas e materiais, a capacidade política da Inglaterra de se contrapor à Alemanha em conjunto com a França era limitada.

A Leste, a França já não podia contar com uma aliança com a Rússia para dissuadir eventuais atos de agressão da Alemanha. Os destinos da Revolução Bolchevique eram incertos. As derrotas sofridas pela Rússia czarista até sua implosão com a Revolução de 1917 pareciam tê-la condenado, aos olhos dos estadistas europeus, ao ocaso de sua posição de grande potência. A garantia da independência da Polônia e a criação de novos Estados-nação criaram um "cordon sanitaire" que isolaria a Rússia da geopolítica européia. Na ausência da Rússia, imaginou Georges Clemenceau, a garantia francesa contra a agressão alemã estaria ao Leste na Polônia e na Tchecoslováquia.

O Tratado de Rapallo (1922) entre a Alemanha e a Rússia normaliza suas relações bilaterais, mas, contribuindo para a percepção de insegurança da França, os dois países passam a considerar a Liga instrumento dos vencedores para perpetuar desigualdades de poder.

À medida que aumentavam os problemas políticos e econômicos domésticos na Alemanha, cresciam os ressentimentos em relação ao Acordo de 1919. A França superou Waterloo, pois se viu integrada ao sistema internacional como potência legítima - afinal, a França não era Napoleão, como entenderam os estadistas do Congresso de Vie- 
na. Mas a Alemanha não podia esquecer Versalhes, porque cada sacrifício quotidiano parecia um momento de expiação.

No fundo, não importava tanto a lógica e o alcance econômico irrealistas das reparações impostas à Alemanha pelos vencedores da Grande Guerra. O que importou foi sua força simbólica e psicológica. Humilhada em Versalhes, a Alemanha perdeu a guerra e territórios, e foi obrigada a desarmar-se e a assumir a culpa pelo conflito. As reparações eram simbólicas, lembranças permanentes de tudo isso para o cidadão comum, acirradas quando o país mergulhou no caos inflacionário. Seu efeito psicológico na estrutura política doméstica alemã foi arrasador. As reparações criaram ressentimentos, rancores, hostilidades que seriam capitalizadas pelo primeiro líder que decidisse, em seus sonhos megalomaníacos, reerguer o Reich.

A ocupação do Ruhr pela França, em 1922, sinalizou ao continente a disposição do país em agir unilateralmente para garantir sua segurança. Pouco adveio dessa iniciativa. A coerção mostrava-se inútil como política em relação à Alemanha. A verdade é que a França e a Inglaterra, por seus próprios movimentos geopolíticos, criavam para si um impasse. A insistência da França em enfraquecer unilateralmente a Alemanha impossibilitava o apoio britânico; a insistência da Grã-Bretanha na conciliação - o que lhe daria nova posição de preponderância entre as potências européias - subestimava seu impacto psicológico para a segurança da França e impossibilitava a colaboração francesa.

Mas as vozes a favor do apaziguamento (appeasement) cresciam na Europa. Era preciso trazer a Alemanha para a ordem internacional. Como notou Taylor (idem:50), consolidava-se a percepção de que a paz seria possível somente com a cooperação do governo alemão.

Gustav Stresemann chegou ao poder na Alemanha em 1923, com o propósito de tornar seu país membro pleno do sistema europeu. Em 
A Crise da Liga das Nações de 1926: Realismo Neoclássico, Multilateralismo...

sua agenda, permaneciam os interesses alemães de pôr fim às reparações, ao desarmamento imposto, à ocupação do Rhineland; e de definir as fronteiras com a Polônia. Stresemann estava disposto a negociar. Seu principal aliado era a pressão dos eventos. Ele acreditava que a questão central não era a revisão dos tratados para reverter a posição de poder alemã; ao contrário, percebia que o reerguimento do poder alemão de modo legítimo, por meio de negociações, levaria inevitavelmente a uma revisão dos tratados. A Alemanha desejava retornar pacificamente à sua posição de grande potência. Stresemann habilmente sugeria que a paz e a revisão dos tratados caminhassem juntas.

Os Acordos de Locarno, assinados em $1^{\circ}$ de dezembro de 1925, marcaram ponto de inflexão nos anos entreguerras. Sua assinatura pôs fim simbólico à Primeira Guerra; seu repúdio, onze anos depois, marcaria o prelúdio da Segunda. Locarno reconciliou a França e a Alemanha. Representou também alívio para a Inglaterra, que se vira como garante da paz européia desde a saída de fato dos EUA dos assuntos do continente, tendo de acomodar as posições vingativas da França. Em última análise, Locarno foi o triunfo do apaziguamento. Deu à Europa esperança real de segurança e suscitou a perspectiva de que somente a integração da Alemanha asseguraria a paz.

Um dos termos de Locarno referia-se expressamente à entrada da Alemanha no Conselho da Liga como membro permanente. Essa era uma demanda central de Stresemann, dentro de sua estratégia diplomática de reintroduzir a Alemanha como potência legítima do sistema europeu. A Inglaterra, ciente do valor do apaziguamento para a segurança no continente, mostrou-se disposta a apoiar a admissão da Alemanha no Conselho. O método da reforma do Conselho não estava definido. Mas, talvez como forma de demonstrar sua nova posição de poder, a Alemanha lançava o princípio de que somente ela deveria ser admitida como membro permanente ${ }^{10}$. 
O caráter dos Acordos de Locarno era, pois, de segurança regional no tabuleiro geopolítico. A fronteira franco-belga-alemã ficava sob garantia da Inglaterra e da Itália; a solução pacífica das controvérsias tornava-se princípio entre as partes. Acima de tudo, começava a mudar o tratamento dispensado à Alemanha. De potência humilhada em Versalhes, tornava-se parte legítima na política européia.

A partir de 1925, parecia delinear-se um procedimento de transferência dos resultados geopolíticos regionais para o campo multilateral. As grandes potências européias buscariam vincular os Acordos ao sistema da Liga das Nações. Ganhava forma o chamado "espírito de Locarno". Surgia a esperança de superação definitiva dos rancores que assolavam o continente.

\section{O processo brasileiro no tabuleiro multilateral: "vencer ou não perder"}

Para o Brasil, a diplomacia multilateral no pós-Grande Guerra apresentou-se como o meio, por excelência, de ganhar espaço na instância de poder que parecia despontar como definidora dos rumos da política internacional. A nova configuração da ordem internacional, com a Liga das Nações em seu núcleo, era percebida como a onda do futuro no sistema internacional. Para a elite brasileira de política externa, a busca por uma posição de poder central no novo tabuleiro multilateral foi essencial na definição da grande estratégia do país, que orientaria suas estratégias e táticas diplomáticas para a nova ordem.

Se prevalece o julgamento corrente de que o exame objetivo dos recursos de poder do Brasil não parecia justificar a demanda por um lugar ao sol ao lado das grandes potências, isso se deve ao erro comum de atribuir a um único fator - recursos militares tangíveis, por exemplo - importância determinante para o poder nacional. A avaliação presente e futura do poder nacional será sempre incompleta caso des- 
A Crise da Liga das Nações de 1926: Realismo

considere seus elementos intangíveis. Nesse sentido, para entender os objetivos que perseguia o Brasil em termos de uma posição de poder central na ordem internacional, não se pode subestimar a força da experiência histórica na definição das percepções sobre o potencial nacional do país.

O sucesso e o prestígio que a diplomacia do Barão do Rio Branco obtivera no continente americano deixaram pesado fardo para as elites de política externa que o sucederam. As iniciativas diplomáticas seriam inevitavelmente julgadas à sombra desse legado. Quão pesado fora o fardo das elites de política externa que tiveram de agir naquela mesma geração, uma década após a morte do Barão do Rio Branco? Que desafio maior poderia haver para um país, como o Brasil da época, do que postular um espaço no palco das grandes potências com o imperativo de sucesso que o passado diplomático lhe legara? Para entender a natureza da atuação exterior do Brasil no período, parece crucial ter em conta a experiência histórica das glórias diplomáticas do Barão do Rio Branco como fio condutor das percepções da elite de política externa sobre o potencial nacional do país e a posição que deveria ocupar na nova ordem.

À luz dessa experiência histórica como um dos delineadores de percepções sobre o potencial nacional do país, convém observar como foi tomando forma a grande estratégia do Brasil, tal qual definida por sua elite de política externa, com vistas a uma posição de poder no centro decisório do tabuleiro multilateral: o Conselho da Liga das Nações.

Sem a participação dos EUA, logo na primeira sessão formal do Conselho, em janeiro de 1920, o Brasil acreditava-se representante do continente americano na Liga, porta-voz dos ideais americanos de prevalência da paz e do direito na nova ordem internacional. Na I Assembléia da Liga, em setembro daquele ano, o país foi reeleito membro temporário do Conselho por mais um novo período - o apoio 
dos EUA valera ao Brasil o primeiro mandato. As sucessivas reeleições do Brasil como membro não permanente do Conselho seriam facilitadas pela ausência de regras claras (Assembléias de 1921 e 1922).

Mas o processo de intensificação da demanda brasileira por um lugar definitivo entre as grandes potências da ordem internacional se dá durante o mandato do presidente Artur Bernardes (novembro/1922 a novembro/1926). Magro, teso, aparentemente impassível, Bernardes foi um homem profundamente angustiado. Suas decisões, mesmo as mais resolutas, pareciam enfrentar dilemas internos, embates pessoais. Jamais perdoou seus adversários políticos - que cresceram significativamente durante seu período como presidente. Via-os como inimigos que precisavam ser combatidos e derrotados. Governando com mão-de-ferro, despertava a revolta, muitas vezes o ódio, de seus opositores. Para o presidente Bernardes, a derrota era a antítese da vitória, não vencer significava perder, princípio duvidoso quando se trata da prática diplomática. Seu nacionalismo ferrenho encontraria campo fértil nos desafios da política externa de seu governo. Bernardes assumiu a Presidência sob estado de sítio, que seria prorrogado várias vezes em seu mandato. A crise do Estado liberal e do sistema oligárquico no Brasil mostrava seus sinais, com dissidências internas e crescente oposição de novos setores da sociedade. Um país convulsionado por crises dificilmente encontra base de consenso sobre as diretrizes de sua política externa. As soluções radicais ganham força em tempos incertos.

Para conduzir o Ministério das Relações Exteriores foi designado o jornalista Félix Pacheco, proprietário do Jornal do Comércio. Pacheco recebeu o cargo sem qualquer experiência no campo da diplomacia. Sua formação como jornalista focalizava os eventos - aquilo que o historiador Fernand Braudel denominaria “os fogos de artifício” do quotidiano. Faltava-lhe a compreensão ampla dos assuntos interna- 
A Crise da Liga das Nações de 1926: Realismo Neoclássico, Multilateralismo...

cionais, dos movimentos conjunturais, das pressões e desafios estruturais da política mundial.

Operava-se, na condução da política externa, importante mudança de estilo, de tom, de ênfase. Se permanecia o objetivo estratégico de obter posição de poder entre as grandes potências que decidiriam os rumos da ordem internacional a partir do tabuleiro multilateral, a forma dessa demanda se alterava. Durante o governo do presidente Epitácio Pessoa (1919-1922), o Brasil manteve na Liga postura low profile, não raro reativa. $\mathrm{O}$ ideal de poder na ordem multilateral era perseguido como um direito, como uma demanda justa que seria oportunamente reconhecida dentro do espírito de civilidade que inspirava aquela ordem. Com Bernardes na Presidência, a conquista do assento permanente no Conselho da Liga tornou-se meta central da ação diplomática brasileira, empreendida paulatinamente com intemperança, à medida que se mostrava frustrado um "direito natural". Nesse ponto, a política externa corria o grave risco de confundir "objetivo estratégico" com "direito natural".

Com efeito, é preciso distinguir duas motivações coexistentes que dominariam esse período e teriam peso na condução da política externa brasileira: uma, de natureza política internacional, que via na posição central da Liga das Nações o coroamento de uma demanda diplomática legítima e natural na ordem futura; outra, de natureza política nacional, que buscava explorar aquela conquista legítima e natural da diplomacia contra oposições políticas domésticas. Por motivos e propósitos distintos, mas por razões similares, que passavam por uma posição de poder natural na Liga correspondente ao potencial nacional do país, a possibilidade de sucesso do pleito em Genebra seduzia a elite de política externa brasileira.

Afrânio de Melo Franco é escolhido pelo presidente Bernardes para representar o Brasil na IV Assembléia da Liga. Melo Franco segue para Genebra em 1923, com instruções para a criação de dois novos assentos permanentes a serem ocupados pelo Brasil e pela Espanha. 
A tática inicial de Melo Franco em Genebra foi criativa. Sugeriu o estabelecimento de um único assento permanente, que seria ocupado pela Espanha até a reintegração da Alemanha ao sistema; o Brasil ocuparia o lugar permanente reservado aos EUA - como cada vez mais os EUA se distanciavam da Sociedade das Nações, o arranjo conferiria, na prática, um assento permanente ao Brasil. Melo Franco reivindicou tal vaga para o Brasil como direito do continente americano - argumentava que o Brasil seria o candidato natural por sua filiação aos ideais da Liga de prevalência do direito internacional. Como a Espanha se recusara a servir de reserva para um assento da Alemanha, Melo Franco fez modificações e propôs que os espanhóis deveriam representar os países hispano-americanos no Conselho. A fórmula é bem recebida pelos membros permanentes, à exceção da Grã-Bretanha. Bernardes e Pacheco superam suas suspeitas iniciais sobre as adaptações feitas por Melo Franco às instruções originais. Adequações táticas são a regra no universo complexo das negociações internacionais. A demanda principal da estratégia diplomática, $\mathrm{o}$ assento permanente, poderia ser atendida.

Os movimentos diplomáticos de 1923 no tabuleiro multilateral incentivaram o governo brasileiro. Os esforços da chancelaria brasileira em seu propósito pelo assento permanente se intensificariam. Em março de 1924, importante passo simbólico é dado para a condução das negociações em Genebra. O Brasil decide criar uma Delegação Permanente junto à Liga, com status de embaixada. Afrânio de Melo Franco foi nomeado seu chefe. A participação intensa do Brasil nos trabalhos da Liga - Conselho, Assembléia, órgãos técnicos, comissões - deveria sublinhar sua legitimidade na obtenção do assento permanente no Conselho. Em sintonia estratégica com Melo Franco, segue em missão o embaixador Raul Fernandes a Londres, Paris, Haia, Praga, Estocolmo e Bruxelas, com o objetivo de defender a candidatura do Brasil. A visita a essas capitais lhe deixa a impressão de que a fórmula adotada por Melo Franco no ano anterior encontraria menor resistência entre os países europeus. Nela, havia o forte argumento da 
A Crise da Liga das Nações de 1926: Realismo Neoclássico, Multilateralismo...

representação do continente americano em uma organização que procurava afirmar-se por sua natureza universalista (Garcia, 2000).

A ação conjunta do Brasil e da Espanha para obtenção do assento permanente não encontrou, todavia, eco diplomático. O Brasil concentrou-se, então, no recurso à suplência dos EUA no Conselho. Tanto Raul Fernandes quanto Melo Franco expressavam acordo sobre a estratégia. Apoiavam-se no fato de que a Liga destinara ao continente americano um assento permanente no Conselho. A suplência provavelmente se tornaria fato consumado, em favor do Brasil. A tática diplomática deixava de ser o aumento do Conselho para a interinidade da posição reservada aos EUA, a ocupação de um lugar já disponível, porém vago.

Durante a V Assembléia da Liga, em setembro de 1924, a Alemanha faz movimento importante por posição no tabuleiro multilateral. Encaminha memorandum aos países-membros do Conselho, pedindo-lhes opinião sobre sua eventual admissão na Liga das Nações. Por sua entrada, estava evidentemente subentendida uma vaga permanente no Conselho.

Para a Alemanha, a admissão na Liga e, em particular, no Conselho, teria profundo significado diplomático. O status de grande potência do país seria novamente reconhecido, mas, sobretudo, chegaria ao fim seu isolamento forçado do sistema de poder europeu, objetivo fundamental da política externa de Stresemann, cuja política de adesão à ordem de Versalhes criava pressão sobre a Inglaterra e a França. Estas se mostravam um tanto desconfortáveis com os princípios da ordem criada por inspiração wilsoniana, mas estavam dispostas a abraçá-los, se esse era o preço da segurança no continente. Tendo isso em vista, a Grã-Bretanha e a França comprometem-se a não objetar os planos alemães por um assento permanente. O Brasil, consultado como membro não permanente, responde que "não possui objeções, a priori, à admissão da Alemanha" (Santos, 2002:10), salien- 
tando, porém, que a questão deveria ser tratada não de modo bilateral, mas sim multilateralmente, entre os membros da Sociedade das Nações.

Encaminhando a questão alemã para o plano multilateral, a diplomacia brasileira procurava espaço político para administrar sua demanda concomitantemente à alemã, insistindo na própria pretensão, quando entrasse em pauta a reivindicação da Alemanha. Um clima de reforma possivelmente favoreceria os objetivos brasileiros. De todo modo, o Brasil foi novamente reeleito como membro temporário.

Na percepção da elite de política externa brasileira sobre as dinâmicas de poder no tabuleiro multilateral, o governo britânico era considerado o principal obstáculo à pretensão do país na nova ordem internacional. O embaixador brasileiro em Londres, Régis de Oliveira, recebido por Chamberlain em abril de 1925, discute a questão da candidatura. Chamberlain, habilmente, lembra ao embaixador que todos os membros não permanentes teriam a mesma aspiração e que sua tarefa "não era apoiar algum país, mas antes justificar escolhas em face das demandas contraditórias e da necessidade de manter um equilíbrio entre os membros permanentes e não permanentes" (idem:11).

Em julho de 1925, o Brasil envia memorandum secreto aos membros do Conselho, expressando sua visão sobre a reforma do órgão. $\mathrm{O}$ principal argumento mantém-se o desequilíbrio na representação geográfica. A Liga correria o risco de se tornar verdadeiro "instrumento da política européia", caso não fosse ajustado tal desequilíbrio. As alternativas que apresentava o Brasil como solução para a distribuição injusta eram ou a ocupação provisória pelo Brasil do assento reservado aos EUA, ou a criação para o país de nova vaga permanente reservada ao continente americano.

Na VI Assembléia da Liga, em 1925, as grandes potências buscaram manter inalterada a composição do Conselho, até que se resolvesse a 
A Crise da Liga das Nações de 1926: Realismo Neoclássico, Multilateralismo...

"questão alemã". A discussão sobre o assento permanente é mais uma vez adiada - agora em função das negociações européias vis-à-vis a Alemanha.

Entre os países da América Latina, cresciam as pressões pelo revezamento do assento de membro temporário do Conselho. A Venezuela propôs resolução que previa renovação obrigatória dos assentos temporários do Conselho a partir da Assembléia seguinte, em 1926. O Brasil teve de comprometer-se a aceitar o rodízio do ano seguinte, para ser novamente reeleito como membro temporário. A opção de manter a condição renovável de membro não permanente parecia ter-se apresentado pela última vez.

Na estrutura política doméstica do Brasil, a participação do país na Liga começava a tomar contornos passionais, com forte teor nacionalista. O desgastado governo do presidente Bernardes começava a descobrir a utilidade das crises externas na mobilização da unidade nacional. A estratégia diplomática em Genebra poderia ser canalizada para ganhos de legitimidade na política doméstica, uma das formas mais obtusas e eficazes de instrumentalização da política exterior de um país. Com as opções se fechando à demanda do Brasil na política internacional e com a difícil situação política interna no país, uma inflexão na política externa mostrava-se atraente. Os contornos de uma solução radical começavam a delinear-se.

Um dia depois da assinatura dos Acordos de Locarno, em $1^{\circ}$ de dezembro de 1925, o tabuleiro geopolítico europeu invadiu decisivamente a agenda multilateral brasileira. Quando Chamberlain informou Melo Franco de que a Alemanha seria admitida no Conselho, parecia absolutamente claro que as questões internacionais européias tinham precedência sobre as questões da Liga, e que estas deveriam necessariamente aceder àquelas.

O três meses que separam a assinatura dos Acordos de Locarno e a crise de março de 1926 revelam como a situação internacional pode 
deteriorar-se rapidamente, quando longos processos paralelos chegam a uma encruzilhada decisiva.

\section{O choque de tabuleiros e a retirada do Brasil da Liga das Nações}

A perspectiva de reforma do Conselho dera ânimo ao Brasil. Locarno parecia apresentar a oportunidade pela qual o Brasil esperara de assumir uma vaga permanente. Melo Franco via no "espírito de Locarno", com a possibilidade de reforma geral do Conselho, a chance definitiva para a pretensão brasileira de uma posição de poder entre as potências centrais da Liga das Nações.

Em janeiro de 1926, nova dinâmica de poder começa a tomar forma no tabuleiro multilateral. Incentivada pela França, a Polônia anuncia sua candidatura a uma vaga permanente. Parecia inevitável aos líderes poloneses que, uma vez no Conselho, a Alemanha procuraria revisar questões geopolíticas vitais, como a do Corredor de Dantzig e de suas minorias na Polônia. O protesto alemão foi imediato. Somente aceitaria sua entrada exclusiva no Conselho. Em meio às reivindicações, Brasil e Espanha renovam suas respectivas candidaturas.

A diplomacia francesa logo percebe que o tabuleiro multilateral não anulava a política de poder tradicional; antes, dava-lhe oportunidade de continuar a geopolítica por outros meios. Desconfianças históricas não se apagam rapidamente para as gerações que viveram experiências traumáticas. Para a elite de política externa francesa, a contenção discreta da Alemanha no tabuleiro multilateral seria uma garantia adicional à segurança que vislumbrava. Além da Polônia e da Alemanha, a França apóia o Brasil e a Espanha. No final de janeiro, após conversa com Briand em Paris, Chamberlain mostrou-se favorável à candidatura polonesa, mas ainda reticente ao pleito brasileiro e espanhol. 
O Brasil percebe o dilema que se operava no tabuleiro multilateral: ou a Liga reconhecia o valor de sua candidatura ao sistema que se pretendia universal, ou daria provas de que era efetivo instrumento da política do poder européia. Evidentemente uma reforma ampla do Conselho, contemplando a Polônia, o Brasil e a Espanha, diluiria o prestígio diplomático que uma admissão exclusiva traria para a Alemanha no palco das grandes potências.

Em 8 de fevereiro de 1926, a Alemanha apresenta seu pedido de admissão à Liga das Nações. O Conselho resolve convocar uma Assembléia Extraordinária para votar a questão a partir de 8 de março.

O Brasil avaliou como "postura desleal" a atitude alemã de pleitear sua entrada exclusiva no Conselho, uma vez que o país se comprometera a apoiar a Alemanha em 1924. O chanceler Pacheco declara, em entrevista ao United Press, que o Brasil permanecia abertamente candidato ao assento permanente. O representante alemão no Rio de Janeiro, Hubert Knipping, observou que sua chancelaria ignorava qualquer outra candidatura oficial. Chamado ao Itamaraty, Pacheco comunica a Knipping que, com a nova postura alemã, o Brasil não mais poderia manter o apoio dado em 1924. Em nota ao governo alemão, o Brasil condiciona seu apoio ao fato de que a Alemanha não fosse o único país admitido no Conselho nem criasse obstáculos à aspiração brasileira. Paralelamente, o embaixador brasileiro em Washington, Gurgel do Amaral, sonda Kellogg sobre a possibilidade de apoio dos EUA às potências européias. Os EUA não estavam dispostos a se envolver. As posições tornam-se inflexíveis.

Ao final de fevereiro de 1926, o veto tomava contornos definitivos para o presidente Bernardes e para o chanceler Pacheco. Em comunicação a Melo Franco, reconhecem que é chegada a hora de gesto peremptório na Liga. O embaixador Melo Franco sabia que, depois de anos de campanha, permanecer na Liga após uma reforma que não contemplasse a aspiração do Brasil seria por demais humilhante para 
o país. Por outro lado, tinha consciência sobre o que representava o veto para o processo europeu de Locarno e para as esperanças que suscitara.

Notando a reticência de Melo Franco em considerar o veto, o presidente escreve-lhe e recorda que o Brasil não possuía qualquer compromisso em relação aos Acordos de Locarno. A escolha do país seria entre "vencer ou não perder".

Na véspera do início da Assembléia Extraordinária, em 7 de março de 1926, o chanceler Pacheco, em expediente ao embaixador Melo Franco, dá instruções explícitas sobre o uso do veto contra a Alemanha, caso as demandas brasileiras não fossem atendidas.

Em reunião secreta no dia 10 de março, o Brasil menciona o texto de sua resposta à Alemanha sobre a não-renovação do apoio dado em 1924, para surpresa dos líderes das grandes potências. As posições começam a se tornar radicais; as decisões, tensas, apressadas, ambivalentes. Na manhã de 12 de março, a delegação alemã propõe reforma que lhe garantisse um assento permanente, reservando à Polônia um não permanente. No mesmo dia, o governo alemão rejeita a fórmula proposta por sua delegação e mantém a postura de que somente a Alemanha deveria ser admitida.

A Suécia propõe renunciar seu assento não permanente para dar lugar à Polônia. O mesmo propõe a Tchecoslováquia, como forma de resolver um impasse: um país neutro (Suécia) seria substituído por outro com interesses geopolíticos nem sempre simétricos aos alemães (Polônia). Stresemann insiste, porém, que qualquer solução, senão a admissão exclusiva de seu país, não deveria sequer entrar em consideração. Sem alternativas, Melo Franco anuncia sua instrução de vetar a admissão alemã. Pedindo confirmação urgente dessa posição ao presidente Bernardes, enfatiza o "terrível erro" de pôr em risco a paz européia. O presidente comunica a Melo Franco a posição definitiva do Brasil: vetar qualquer aumento de membros permanen- 
tes que não contemple o país. Retroceder em relação ao veto já era politicamente impossível.

Em reunião no dia 15 de março, Melo Franco confirma que o Brasil estará disposto a usar o veto. Não resta dúvida, como assinala Norma Breda, de que as potências européias subestimaram o empenho brasileiro, o quanto significava o projeto da Liga para a diplomacia do país e sua capacidade de exercer o poder de veto. Somente depois do anúncio de 15 de março, quando não mais existia possibilidade de mudança de curso tático para qualquer dos atores envolvidos, Briand e Chamberlain decidem empenhar-se. Os respectivos embaixadores no Rio de Janeiro, Conty e Alston, são enviados para tentar convencer o presidente Bernardes a alterar suas instruções. O encontro foi inútil. As janelas de negociação já se haviam fechado. Bernardes não se seduzirá pelos argumentos dos embaixadores, com menções ao papel de "grande potência mundial do Brasil" ou à "demanda legítima [do Brasil], incontestavelmente consubstanciada no Direito e na lógica" (Garcia, 2000), em relação ao seu lugar no Conselho.

Na manhã do dia 17 de março, horas antes da última reunião do Conselho para discutir a entrada da Alemanha, Melo Franco faz seu último esforço de convencimento do presidente.

À tarde, o Brasil confirma seu veto à admissão da Alemanha. A Assembléia, reunida, aprova a proposta de Briand de adiar a decisão para setembro. Na ocasião, Melo Franco justifica a posição brasileira em discurso, lembrando que a obra de Locarno deveria ser parte da Liga, e não a Liga parte de Locarno.

A política de conciliação européia no tabuleiro geopolítico encontrava-se barrada no tabuleiro multilateral.

A obra de Locarno não desabou - não naquele momento - pela ação diplomática do Brasil. Mais tarde, "a Alemanha foi admitida na Liga 
das Nações, depois de mais atrasos do que eram esperados" (Taylor, 1996:55).

Após a crise de março de 1926, foi criada uma comissão para estudar a composição do Conselho, ou seja, como notou Hilton, "para encontrar um meio de remover o Brasil” (Hilton, 1986:22).

Durante reunião do Conselho, em 10 de junho de 1926, sem apoio tanto na Europa quanto no continente americano, o Brasil renunciou seu assento temporário, criticando o esvaziamento dos ideais de Wilson - em vez de "preparar o futuro", a Liga propunha "perpetuar o passado".

Dois dias depois, em 12 de junho de 1926, o Brasil notifica sua retirada da Liga das Nações.

\section{Conclusão: A Natureza da Política Externa}

Na ordem internacional pós-Grande Guerra, a Liga das Nações, por inspiração dos ideais wilsonianos, deveria ter papel central nas relações internacionais. A partir de uma organização internacional, prevaleceriam as regras do direito, restringindo o exercício da política do poder. A longo prazo, a paz e a segurança internacional estariam asseguradas pela renúncia às práticas do passado e pela adesão aos ideais para o futuro.

A diplomacia brasileira apostou todas as suas fichas na nova ordem internacional. Julgava que a Liga seria o centro decisório, a instituição condutora do futuro da política mundial. Essa perspectiva sobre a importância que teriam posições de poder no tabuleiro multilateral e a percepção sobre o potencial nacional do país que sua experiência histórica informava deram o tom à grande estratégia brasileira. 
No governo do presidente Artur Bernardes, como notou Eugênio Vargas Garcia, a meta do assento permanente no Conselho da Liga tornou a política externa "monotemática" e "messiânica", servindo para contrabalançar sua impopularidade doméstica. Segundo a interpretação de Garcia, o Brasil usou, na Liga, uma diplomacia complexa, entre grandes potências e potências menores, entre pragmatismo e principismo, entre realismo e idealismo, mas foi uma ação minada por uma misperception inicial quanto às possibilidades internacionais do país. Sobre essa carência de realismo inicial, para ele sinônimo de escassez de recursos materiais de poder, Stanley Hilton (idem:19) observou que: "O Brasil (...) era um país militar e economicamente fraco, fato que praticamente garantia que os principais países europeus não o aceitariam como parceiro do mesmo nível”.

A partir dos Acordos de Locarno de 1925, a superação de diferenças sinalizava a reintegração da Alemanha à ordem européia. Mas havia um preço político multilateral. A Alemanha deveria ser admitida sozinha como membro permanente do Conselho da Liga das Nações. Os interesses brasileiros na organização eram postos em xeque. Com a radicalização da política internacional das potências européias e da política doméstica brasileira, observou Eugênio Vargas Garcia, o governo do presidente Artur Bernardes procurou camuflar o fracasso de seu objetivo principal ("vencer") recorrendo a demonstração de força em Genebra ("não perder”).

Apreciada em perspectiva, porém, verifica-se que a deflagração da crise de 1926 pelo governo Bernardes não deve ser vista como definidora da natureza da política externa brasileira no período. O exame no marco teórico das relações internacionais sugere que um processo mais amplo e complexo estava em curso no sistema internacional. $\mathrm{O}$ processo de radicalização do presidente Bernardes foi uma mudança de estilo na condução da política externa, associada a idiossincrasias e vicissitudes políticas domésticas, e não de natureza da política externa, que se relacionava ao objetivo estratégico de uma posição de 
poder central na ordem internacional, correspondente ao potencial nacional do país.

Na elite diplomática nacional, a raiz mais profunda da percepção sobre o potencial nacional do Brasil, que informaria a definição e a natureza da política exterior no período, estaria na idéia do legado de sua experiência histórica internacional. Foi a busca da permanência, de manter e aprofundar a herança do Barão do Rio Branco, de conquistar a posição ao lado das grandes potências na instituição-chave que, supunha-se, regeria a nova ordem internacional.

Se houve uma misperception fundamental, esta deve ser atribuída às expectativas quanto à Liga das Nações e ao seu papel na nova ordem - algo que não pode ser creditado exclusivamente ao Brasil. Boa parte do mundo acreditava que a "comunidade de poder" da Liga substituiria a estrutura anárquica do sistema internacional e suas dinâmicas tradicionais. Todos os barcos navegavam no mesmo oceano de percepções equivocadas.

A política externa brasileira do período não teve a natureza de uma "política externa de prestígio", que, na definição clássica de Hans Morgenthau (1985:87), procura "impressionar outras nações (...) com o poder que acredita, ou quer que outras nações acreditem, possuir". Se o fosse, se não houvesse a crença naquela nova ordem mundial, como explicar o fato de ter sido levada às últimas conseqüências políticas, empenhada aos últimos recursos humanos e financeiros, disposta a comprometer inclusive relações diplomáticas históricas? Tampouco a natureza da política externa brasileira na crise de 1926 foi o produto de uma "diplomacia bonapartista", que usa aventuras internacionais para desviar as atenções de dificuldades políticas domésticas. O caráter da política externa jamais pode ser julgado por um evento específico. Se é certo que as pressões da estrutura política doméstica do Brasil conduziram o presidente Bernardes a buscar mecanismo de legitimação e apoio por meio de ação externa radical, tal 
A Crise da Liga das Nações de 1926: Realismo

Neoclássico, Multilateralismo...

motivação, incidental, não deve ofuscar a natureza fundamental do processo internacional.

O projeto de uma posição de poder entre as grandes potências na Liga das Nações foi sistematicamente conduzido por meio de estratégias e táticas diplomáticas, perseguido por anos a fio, em um longo processo consensual de sua elite de política externa. Do lado brasileiro, o estopim da crise de 1926 pode ser creditado a uma série de atitudes impulsivas, que se explicam pela personalidade e situação política dos principais decisores nacionais, mas não se confunde com a política de Estado para a Liga das Nações. Do lado das grandes potências européias, a única questão que parecia interessar era a reintegração da Alemanha ao sistema internacional. Percebia-se um claro desencontro entre as dinâmicas por posições de poder nos tabuleiros multilateral e geopolítico do sistema internacional.

No horizonte do longo prazo, ao se comparar os países da Europa ao Brasil, verifica-se uma absoluta dissonância de percepções quanto ao papel que a Liga deveria exercer na ordem internacional. Para o Brasil, o multilateralismo da Liga deveria significar o fim, ou pelo menos o apaziguamento, da política de poder tradicional nas relações internacionais; para as potências do Velho Mundo, o multilateralismo era a continuação da geopolítica por outros meios. Considerando que a condição estrutural do sistema internacional permanecia anárquica, superestimou-se a expectativa de que uma instituição multilateral suplantaria a importância do poder nas relações internacionais. Desconsiderando que uma instituição multilateral se tornara parte integrante da vida internacional, subestimou-se o fato de que as dinâmicas no tabuleiro multilateral passariam a afetar o próprio funcionamento do tabuleiro geopolítico tradicional. Assim o demonstrou o episódio de 1926.

Parece existir motivação profunda na natureza da política externa brasileira, quando se examinam os processos da política internacio- 
nal do período, as percepções e as grandes linhas estratégicas da elite nacional envolvida. Do ponto de vista da percepção sobre o sistema internacional, foi essencial a certeza de que a Liga das Nações se constituiria no centro das relações internacionais, de que o tabuleiro multilateral substituiria o tabuleiro geopolítico tradicional. Do ponto de vista da percepção sobre o potencial nacional do país, foi decisiva a luz da experiência histórica que lançava o legado diplomático do Barão do Rio Branco. Com o objetivo de uma posição de poder na Liga cristalizado em interesse nacional, as elites de política externa perseguiram, por meio de estratégia consistente, durante anos, um lugar ao sol entre as grandes potências da nova ordem que se desenhava.

A natureza da política externa brasileira no período foi a de uma política externa de status quo, de conquista de posição central de poder na nova ordem internacional, que teria a Liga das Nações como a última instância das relações internacionais. Como definiu Morgenthau (idem: 53; 56), a política externa de natureza "status quo" é a que busca a manutenção da distribuição de poder, assim como aumentos e ajustes de posições de poder dentro da ordem internacional existente.

A crise do Conselho de 1926 deve ser entendida, portanto, em dois planos, como o choque entre dois processos distintos, porém interdependentes, que se encontram no plano multilateral: a questão da segurança européia e da entrada da Alemanha na Liga, por um lado; a culminação dos esforços brasileiros de obter um assento permanente no Conselho da Liga, por outro.

Nesse sentido, o Brasil não criou sozinho a crise de 1926. Desde o início da década de 1920, vinha, ano a ano, perseguindo o objetivo de conseguir um assento permanente no Conselho. Não foi o Brasil que decidiu tornar a revisão do Conselho uma questão crítica para a segurança européia naquele ano. Os líderes europeus escolheram desconsiderar a autoridade da Liga das Nações, subordinando-a às suas de- 
A Crise da Liga das Nações de 1926: Realismo Neoclássico, Multilateralismo...

cisões geopolíticas regionais. Após Locarno, ficou claro que as questões européias eram importantes demais para deixar que países como o Brasil tivessem poder de decisão sobre elas, por meio de instrumentos multilaterais. O tabuleiro geopolítico mostrava-se superior ao multilateral, mas este dava sinais de sua existência. E nesse espaço o Brasil barrara um processo fundamental das grandes potências européias.

Não houve "fiasco" absoluto da diplomacia brasileira no episódio de $1926^{11}$. Ao ver-se derrotada a política externa brasileira de "status quo", que vislumbrava uma posição central entre as grandes potências na Liga das Nações, produziu-se objetivamente uma vitória do multilateralismo. Demonstrava-se, pela primeira vez nas relações internacionais, ainda que de modo efêmero, a importância que o sistema multilateral poderia ter para a política externa brasileira.

$\mathrm{O}$ espaço político multilateral, esse tabuleiro típico do século $\mathrm{XX}$, dava sinais de vida, mostrando sua capacidade de afetar o tabuleiro clássico das relações geopolíticas. Quando o embaixador Melo Franco observa que "a obra admirável de Locarno" deveria entrar no quadro da Liga "e não a Liga na construção política de Locarno", tipifica-se o conflito entre os dois tabuleiros do sistema internacional - e, para as potências européias, o desejo de predominância do geopolítico.

Para a diplomacia brasileira, 1926 desfez o projeto de uma posição de poder na Liga das Nações que correspondesse às suas aspirações históricas. Na exposição sobre os motivos de sua retirada da Liga das Nações, o Brasil lamentava: "A Sociedade das Nações se transforma, pelo abandono do ideal americano que a criou como instituição destinada a preparar o futuro, em outra que, no fundo, parece propor-se a perpetuar o passado" (MRE, 1926: anexo A).

A crise de 1926 foi um sinal, como observou Chris Leuchars (2001), de que as idéias do século XX estavam se movendo depressa demais para as mentes do século XIX. Mais do que isso, uma organização in- 


\section{Braz Baracuhy}

ternacional no tabuleiro multilateral, resultado dessas idéias, mostrava-se influente demais para as mentes habituadas à política do poder no tabuleiro geopolítico tradicional do século XIX.

\section{Notas}

1. "Treinado na escola do realismo do poder", como observou Rubens Ricupero, o Barão do Rio Branco foi “o último grande estadista e diplomata desse século XIX brasileiro, plenamente homem do seu tempo nos valores e objetivos, no método e estilo" (Ricupero, 2000:48-49).

2. A tradução waltziana do modelo dedutivo da microeconomia neoclássica para a análise da política internacional pode ser vista como a segunda grande investida "científica" - depois do behaviorismo na década de 1950 - sofrida pelas abordagens clássicas ou tradicionais das Relações Internacionais dentro da academia, em especial da norte-americana.

3. Para excelente perspectiva sobre diferentes níveis de análise que podem ser integrados nas explicações históricas sobre política externa, ver Kennedy (1982).

4. Kenneth Waltz utilizou a diferenciação dos níveis, pela primeira vez na disciplina, em seu livro Man, the State, and War (1959), cuja resenha de David Singer daria origem ao famoso artigo deste: "The Level-of-Analysis Problem in International Relations" (1969), base metateórica de várias formulações posteriores na disciplina.

5. O realismo neoclássico, como o realismo clássico antes dele, trata de não confundir "rigor teórico" com "exatidão científica" ao abordar esse objeto esquivo, porque essencialmente político, que são as relações internacionais e sua condução por meio da diplomacia. Na medida em que focaliza o decisor e o processo decisório, suas condicionalidades e seus dilemas, a teoria internacional agrega em relevância política, pois "quando as cartas estão sobre a mesa, está-se diante do desconhecido e será preciso fazer julgamentos baseados em informações incompletas e conhecimentos teóricos. É preciso apostar e rezar para ter apostado corretamente." (Morgenthau, 1970:83).

6. Devo a imagem dos tabuleiros a Joseph Nye (2002), embora este autor a utilize em relação a dimensões do poder internacional, e não, como procuro em- 
A Crise da Liga das Nações de 1926: Realismo Neoclássico, Multilateralismo...

pregar, em relação à natureza ontológica dos espaços históricos de interações no sistema internacional.

7. O livro A Construção da Ordem, de José Murilo de Carvalho (1996), constitui minucioso estudo da elite política imperial brasileira na construção da ordem monárquica. Para o autor, as elites políticas são grupos especiais de elite, marcados por características que os distinguem tanto das massas quanto de outros grupos de elite (Mills, 2000).

8. Como notou Soares de Lima (1994), esse paradigma se definia pela aproximação aos EUA - em “aliança não-escrita”, sempre que possível - como instrumento que elevaria os recursos de poder do país, aumentando sua capacidade de negociação e seu status internacional.

9. Na Conferência realizada na cidade suíça de Locarno, a partir de outubro de 1925, as potências européias discutiram questões não completamente resolvidas ao final da Grande Guerra, sobretudo desconfianças recíprocas entre a França e a Alemanha. O resultado foi um conjunto de tratados, conhecidos como "Acordos de Locarno", louvados como o início efetivo de uma era de paz na Europa. Seus principais aspectos foram os seguintes:

(a) a França, a Alemanha e a Bélgica comprometiam-se a respeitar suas fronteiras. A Alemanha comprometia-se a jamais atacar a França e a Bélgica como o fizera em 1914; a França e a Bélgica renunciavam ao uso da força contra a Alemanha, como ocorrera em 1923, com a ocupação do Vale do Ruhr;

(b) a Grã-Bretanha e a Itália seriam fiadoras desses termos;

(c) a França comprometia-se a apoiar a Polônia e a Tchecoslováquia, caso surgisse confronto entre elas e a Alemanha; e

(d) todos os países envolvidos concordavam em jamais recorrer à guerra, caso surgisse disputa entre eles.

10. A França vislumbra, na reforma do Conselho, oportunidade para apoiar a entrada da Polônia também como membro permanente. Os porquês desse apoio não são claros. Talvez a França, insistindo na eleição de sua aliada, estivesse buscando reproduzir no tabuleiro multilateral o equilíbrio de poder do tabuleiro geopolítico europeu. A Polônia funcionaria como contrapeso à Alemanha.

11. Refiro-me especificamente à vitória, ainda que efêmera, do multilateralismo; ao fato de que a ação diplomática brasileira demonstrou a capacidade de o tabuleiro multilateral afetar as dinâmicas no tabuleiro geopolítico das grandes potências. Devo a observação à leitura atenta deste artigo feita pelo meu colega Eugênio Vargas Garcia, que, em recente livro sobre a política externa brasileira durante a década de 1920, assinala as consequiências geopolíticas negativas daquela ação multilateral (Garcia, 2006:598). 


\section{Referências} Bibliográficas

CARVALHO, José Murilo de. (1996), A Construção da Ordem: A Elite Política Imperial. Rio de Janeiro, UFRJ.

CERVO, Amado e BUENO, Clodoaldo. (2002), História da Política Exterior do Brasil. Brasília, Editora UnB.

FRIEDBERG, Aaron. (1988), The Weary Titan: Britain and the Experience of Relative Decline, 1895-1905. Princeton, Princeton University Press.

GARCIA, Eugênio Vargas. (2000), O Brasil e a Liga das Nações (1919-1926). Porto Alegre, Editora da UFRGS.

(2006). Entre América e Europa: A Política Externa Brasileira na Década de 1920. Brasília, Editora UnB.

HILTON, Stanley. (1980), "Brazil and the Post-Versailles World: Elite Images and Foreign Policy Strategy, 1919-1929”. Journal of Latin American Studies, vol. $12, \mathrm{n}^{\mathrm{o}} 2$.

(1986), "Afrânio de Melo Franco e a Diplomacia Brasileira, 1917-1943”. Revista Brasileira de Política Internacional, vol. 18, nº 1 .

HOWARD, Michael. (2001), "Grand Strategy in the Twentieth Century". Defence Studies, vol. 1, nº 1 .

KENNEDY, Paul. (1982), "The Kaiser and German Weltpolitik: Reflexions on Wilhelm II's Place in the Making of German Foreign Policy", in J. Röhl e N. Sombart, Kaiser Wilhelm II: New Interpretations. Cambridge, Cambridge University Press.

(ed.). (1991), Grand Strategies in War and Peace. New Haven, Yale University Press.

KISSINGER, Henry. (1994), Diplomacy. New York, Simon \& Schuster.

KUPCHAN, Charles. (2002), The End of the American Era: US Foreign Policy and the Geopolitics of the Twenty-first Century. New York, Alfred Knopf.

LEUCHARS, Chris. (2001), "Brazil and the League Council Crisis of 1926". Diplomacy \& Statecraft, vol. 12, nº 4 . 
A Crise da Liga das Nações de 1926: Realismo Neoclássico, Multilateralismo...

MILLS, C. Wright. (2000), The Power Elite. New York, Oxford University Press.

MORGENTHAU, Hans. (1970), "Conference Discussion on Theory”, in N. Palmer, A Design for International Relations Research: Scope, Theory, Methods, and Relevance. Philadelphia, American Academy of Political and Social Science.

. (1985), Politics among Nations (6-ed.). New York, McGraw-Hill.

MRE - Ministério das Relações Exteriores. (1926), "Relatório do Ministério das Relações Exteriores”. Disponível em <http://brazil.crl.edu/bsd/bsd/hartness/relacoes.html>. Press.

(2002), The Paradox of American Power. New York, Oxford University

RICUPERO, Rubens. (2000), Rio Branco: O Brasil e o Mundo. Rio de Janeiro, Contraponto.

ROSE, Gideon. (1998), "Neoclassical Realism and Theories of Foreign Policy". World Politics, vol. 51, nº 1 .

SANTOS, Norma Breda dos. (1996), Le Brésil et La Société des Nations (1920-1926). Tese de Doutorado, nº 557, Universidade de Genebra.

. (2002), The Brazilian “Fiasco". Manuscrito.

SCHWELLER, Randall. (1996), “Neorealism's Status-Quo Bias: What Security Dilemma”, in B. Frankel (ed.), Realism: Restatements and Renewal. London, Frank Cass.

. (1997), Deadly Imbalances. New York, Columbia University Press.

SINGER, J. David. (1969), “The Level-of-Analysis Problem in International Relations”, in J. Rosenau (ed.), International Politics and Foreign Policy. New York, The Free Press.

SOARES DE LIMA, Maria Regina. (1994), "Ejes Analíticos y Conflicto de Paradigmas en la Política Exterior Brasileña”. América Latina/Internacional, vol. $1, \mathrm{n}^{\mathrm{o}} 2$. . (2001), Teorias e Conceitos de Política Internacional. Manuscrito. 


\section{Braz Baracuhy}

TAYLOR, A. J. P. (1996), The Origins of the Second World War. New York, Touchstone.

WALT, Stephen. (2002), “The Enduring Relevance of the Realist Tradition”, in I. Katznelson e H. Milner, Political Science: The State of the Discipline. New York, W.W. Norton \& Company.

WALTZ, Kenneth N. (1979), Theory of International Politics. New York, McGraw-Hill.

WOHLFORTH, William. (1993), The Elusive Balance: Power and Perceptions during the Cold War. Ithaca, Cornell University Press.

ZAKARIA, Fareed. (1998), From Wealth to Power: The Unusual Origins of America's World Role. Princeton, Princeton University Press. 


\section{Resumo}

\section{A Crise da Liga das Nações de 1926: Realismo Neoclássico, Multilateralismo e a Natureza da Política Externa Brasileira}

O artigo analisa a natureza da política externa brasileira na crise da Liga das Nações (1926), a partir de modelo teórico do realismo neoclássico. As dinâmicas por posições de poder nos tabuleiros geopolítico e multilateral do sistema internacional e as percepções e estratégias diplomáticas da elite de política externa brasileira são consideradas no estudo teórico.

Palavras-chave: Teoria das Relações Internacionais - Realismo Neoclássico - Política Externa Brasileira - Crise da Liga das Nações (1926)

\section{Abstract}

\section{The League of Nations Crisis of 1926: Neoclassical Realism, Multilateralism, and the Nature of Brazilian Foreign Policy}

The article analyzes the nature of Brazilian foreign policy in the crisis of the League of Nations (1926) from a neoclassical-realist theoretical perspective. Within this theoretical framework, the dynamics of power positioning in the geopolitical and multilateral chessboards of the international system and the perceptions and diplomatic strategies of the Brazilian foreign-policy elite are taken into account.

Key words: International Relations Theory - Neoclassical Realism Brazilian Foreign Policy - Crisis of the League of Nations (1926) 